\title{
Las lugartenencias de escribanías como conflicto: un ejemplo de la época de los Reyes Católicos
}

\author{
Maria del Pilar Rabade Obrado *
}

Durante el reinado de los Reyes Católicos, se produce un intento de profunda renovación en el seno de la institución notarial ', que tanto descrédito habia ido acumulando durante los tres primeros cuartos del siglo $X V$, debido a la desidia de Juan II y Enrique IV, incapaces de enfrentarse a los múltiples problemas que planteaba el colectivo de notarios y escribanos ${ }^{2}$.

Una de las cuestiones que ocupará lugar primordial en la reforma auspiciada por Isabel y Fernando será la relativa a la provisión de los oficios de escribania ${ }^{3}$, encauzándose la nueva normativa propuesta esencial-

* Universidad Complutense (Madrid).

En los mismos inicios del reinado, durante las Cortes de Madrigal de 1476, mostraron Isabel y Fernando sus ansias por devolver su perdido brillo a la institución notarial, si bien la reforma queda en suspenso hasta mejor ocasión, debido a la existencia de problemas más graves (Cortes de los Antiguos Reinos de León y Castilla, vol. IV. Madrid 1882, pág. 106, n. ${ }^{\circ}$ 109). Pocos años despues, en las Cortes de Toledo de 1480, se afrontará ya clara y valientemente esta reforma. sustentada sobre tres grandes pilares: el control numérico de los escribanos; su capacitación profesional; los procedimientos de acceso a los oficios de escribania. La cuestion ha sido ampliamente estudiada por Bono, J., Historia del derecho notarial español, 2 vols. Madrid 1982, págs. 291 y ss., vol. I. Su análisis del tema le hace llegar a la conclusión de que es en este momento cuando se impone "una primera y eficaz politica notarial castellana".

Tanto Bono, J., Op. cit, pág. 276 y ss., vol. II, como Arrieas Arranz, F., "Los escribanos de Castilla en el siglo xv», Centenario de la Ley del Notariado, vol. I (Sección Histórica). Madrid 1963, describen la situación con negras tintas.

${ }^{3}$ Según Arribas Arranz F., Op. cit., pág. 197 y ss., es una de las cuestiones esenciales que se plantean en relación con la institución notarial, debido, entre otras cosas, a su incidencia sobre el ejercicio del oficio. 
mente hacia la liquidación de abusos y corruptelas de diversa indole ${ }^{4}$, que habia proliferado a lo largo de los primeros setenta y cinco años de la centuria.

Este trabajo pretende realizar un acercamiento a esta problemática, utilizando para ello la información que ofrece cierto documento del Archivo General de Simancas ${ }^{5}$, referido al pleito que, por la provisión de la escribania de la villa de Ponferrada y su tierra, enfrentó a la citada localidad y a Juan Álvarez de Toledo, oficial de cierto rango en la Corte de los Reyes Católicos. Dicho pleito permite una aproximación a esta cuestión, delimitando aquellos aspectos de la misma que se conforman - desde el punto de vista de los contemporáneos- como fundamentales, señalando toda una serie de problemas cuya incidencia podria ser extrapolada acertadamente a otras villas y ciudades del reino ${ }^{6}$.

\section{LOS PROTAGONISTAS}

El primer protagonista de nuestro pleito es la villa de Ponferrada. Situada en la actual provincia de León, próxima ya a tierras gallegas, contaba, juntamente con su tierra, en el momento en que se inicia el pleito que se va a analizar, entre 500 y 700 vecinos $^{?}$. La localidad habia sido testigo, a lo largo de los primeros años del reinado de Isabel y Fernando, de grandes turbulencias, provocadas por la revuelta protagonizada por su dueño y señor, Don Rodrigo, Conde de Lemos, que no dudó en enfrentarse contra sus legítimos soberanos manteniendo la villa levantada contra aquéllos durante un cierto lapso de tiempo. Sofocada la sublevación,

\footnotetext{
${ }^{4}$ Realmente, el problema más importante que conllevaba la provisión de este oficio era el relativo a la cualificación profesional de aquéllos que a él accedian. Los monarcas mostraron siempre una evidente preocupación por dotar at reino de escribanos capaces, tal como pone de manifiesto Bono, J., Op. cit.

'Archivo General de Simancas (desde ahora, AGS), Consejo Real, Ig. 18, n. 7 . Cada vez que se aluda al pleito a partir de este momento se obviará esta referencia documental.

${ }^{6}$ Para ratificar este aserto, baste cotejar la información que suministra este pleito con los datos que, en torno a las cuestiones que aquí se van a tratar, ofrece Corral Garcia, E., El escribano de concejo en la Corona de Castilla (siglos x/ al xvII). Burgos 1987.

Al menos, tal es lo que afirman algunos de los testigos presentados por la propia villa. Asi, Juan Gallego cifra en 500 el número de vecinos que habitaban tanto en la localidad como en su tierra (fol. $8 \mathrm{v}$ ). Por su parte, Fernán Folle aumenta la cifra, afirmando que existian entre 600 y 700 vecinos; esta segunda parece ser opinión autorizada, pues Folle habia ocupado varios oficios de carácter municipal en Ponferrada, lo que le obligaba a estar más al tanto de las realidades locales (fol. $9 \mathrm{v}$ ).
} 
los monarcas se mostraron dispuestos a perdonar al joven Conde, pero exigieron, entre otras compensaciones, la entrega de la villa con su tierra ${ }^{8}$.

De esta forma, Ponferrada quedó integrada en el realengo, aprestándose a vivir una nueva etapa de su historia, caracterizada por la pertenencia directa a la Corona, hecho que tenía que llevar aparejadas, indudablemente, toda una serie de novedades. $Y$ entre estas innovaciones se ha de citar la nueva manera de proveer sus oficios de escribania, lo que -a su vez- incidiria sobre la forma en que se ejercian dichos oficios.

El segundo protagonista es Juan Álvarez de Toledo, o Juan Álvarez Zapata, pues por ambos nombres era conocido en la Corte de los Reyes Católicos. Oficial al servicio de los soberanos, pertenecia a una familia marcada por una evidente dedicación al servicio de la Corona, dedicación ejemplificada de manera paradigmática en la carrera de su miembro más ilustre, Fernando Álvarez de Toledo, el rnás destacado de los secretarios regios que se situaron al servicio de isabel y Fernando ${ }^{9}$.

\footnotetext{
${ }^{8}$ Dicho enfrentamiento esta inextricablemente unido a las circunstancias un tanto peculiares que marcaron el acceso de Don Rodrigo Enriquez Osorio al titulo condal, debido a su condición de bastardo. En efecto, su padre, único hijo varón de Pedro Álvarez Osorio, Conde de Lemos, habia fallecido sin dejar descendencia legitima, cosa que no pareció importar en exceso al anciano Conde, dispuesto a apoyar a su nieto, por más que fuese ilegitimo, hecho que le llevó no sólo a nombrarle heredero de su titulo y de todas sus posesiones, pues también obtuvo una bula papal de legitimación. La situación se complicó todavia más por las reclamaciones de Rodrigo Alonso Pimentel, Conde de Benavente, cuya nuera, la Marquesa de Villafranca, era la Mayor de las hijas del difunto noble, y, por tanto, su legitima heredera. La situación obligó a Rodrigo a enfrentarse con su tia, aunque los soberanos terciaron antes de que ambos pretendientes recurrieran a la fuerza, conminándoles a someter el caso a la decisión de los tribunales de justicia. Rodrigo, ante el cariz que estaba tomando el asunto, se rebeló contra los propios monarcas, terminando la rebelión con su derrota, pronto paliada por la generosidad de isabel y Fernando, que permitieron que el impulsivo joven mantuviera, a pesar de todo, el titulo condal. El episodio encuentra eco en las páginas de algunos de los cronistas de los Reyes Católicos. Por ejemplo, ver Pulgar, H. del, Crónica de los Señores Reyes Católicos Don Fernando y Doña Isabel, vol. Ill de las Crónicas de los Reyes de Castilla, t. 70 de la Biblioteca de Autores Españoles. Madrid 1953, pág. 381, asi como págs. 442-443. También ha levantado el interés de los historiadores contemporáneos, como es el caso de GARCiA ORO, J, que le ha dedicado algunas páginas en su articulo "La nobleza gallega en el siglo xv", Actas de las I Jornadas de Metodologia Aplicada. Santiago de Compostela 1975, vol. II, págs. 293-299, asi como en su monografia La nobleza gallega en la Baja Edad media. Las casas nobles y sus relaciones estamentales. Santiago de Compostela 1981. Ver, igualmente, SuArez Fernandez, L., Los Reyes Católicos. Fundamentos de la monarquia. Madrid 1989, págs. 119-125, sin olvidar el ya clásico artículo de Moxo, S. de, "De la nobleza vieja a la nobleza nueva".

${ }^{9}$ Sobre este personaje, ver Rabade Obrado, M. P., Los judeoconversos en la Corte y en la época de los Reves Católicos. Madrid 1991, págs. 509-515, 539-551, 624-639, 744-774 y 877 886.
} 
Es indudable la existencia de un parentesco entre ambos oficiales, si bien el mismo no puede precisarse de forma exacta, pues la coincidencia de nombre y apellidos, la coincidencia también en el empleo indistinto de los apellidos Zapata y Toledo, hace muy dificil determinar si se trata de un hermanastro de Fernando, o de uno de sus sobrinos, hijo de uno de sus hermanos, Luis Álvarez de Toledo. Las circunstancias cronológicas en las que parece desarrollarse su actividad, desplegada, primordialmente, a lo largo de los años que se sitúan a caballo entre el siglo $x v$ y el $\mathrm{x} v$, inducen a aceptar como más posible la segunda de las dos hipótesis esgrimidas.

Indudablemente, Juan estaba "especializado" en tareas de corte financiero, tal como demuestra claramente su actividad en los últimos años del siglo xv y los primeros de la siguiente centuria. En 1492 consta como pagador de los peones y de la armada del Reino de Granada, destinados a defender las tierras recién reconquistadas de posibles ataques externos ${ }^{10}$; desde 1496 se encarga, además, de efectuar el pago de los gastos de la Despensa de la reina ${ }^{11}$.

Juan perseveró en estos oficios durante largos años ${ }^{12}$, sin descuidar por ello sus negocios privados, cifrados fundamentalmente en el arren-

10 Sobre sus primeros años de ejercicio de este oficio -de 1492 a 1494- ofrece datos de gran interés Ladero Quesada, M. A., Granada después de la conquista. Repobladores y mudéjares. Granada 1988, pàg. 192. También posteriormente, su actividad como pagador queda reflejada abundantemente en la documentación. A modo de ejemplo, ver AGS, Libros de Cédulas de Cámara, Ib. $11-2 .^{\circ}$, fol. 30v (Burgos, 21 de julio y 9 de agosto de 1495); fol. $126 \mathrm{v}$ (dos cédulas, fechadas ambas en Burgos, 16 de noviembre de 1495); fol. 150v (dos céduias, datadas en San Mateo, 1 de enero de 1495); fol. 215r (Almazán. 16 de julio de 1496)...

"Tal como consta en AGS, Casa Real, Ig. 43, n." 81, que contiene su asiento como oficial encargado de esta labor, fechado a 2 de junio de 1496.

${ }^{12}$ Aunque la información documental acerca de la actividad de Juan Álvarez Zapata como oficial regio se corta bruscamente en 1496, a partir de 1501 la documentación nos ofrece nuevos datos sobre su actividad al servicio de los soberanos, mostrando como seguia ostentado los dos oficios ya citados. Sobre su actividad de pagador, ver LADERO QUESADA, M. A., Op. cit., pág. 193, asi como AGS, Libros de Cédulas de Cámara, 1b. 5, fol. 53v. n. 143 (Granada, 8 de mayo de 1501). En cuanto a su oficio de despensero de la reina, ver AGS, Libros de Cédulas de Cámara, ib. 5, fol. 114r, n. 248 (Granada, sin dia ni mes, 1501); fol. $303 r, n .{ }^{\circ} 1.366$ (Granada, 31 de octubre de 1501), asi como AGS, Casa Real, Ig. 43, n. 168. Se conocen tambièn algunos datos sobre la inspección a que fueron sometidas sus cuentas por parte de un enviado regio, Juan de Loarte, entre 1503 y 1504, información suministrada por AGS, Casa Real, Ig. 3, n. ${ }^{\circ} 86,87$ y 526 . Álvarez de Toledo debió de salir bien parado, pues se puede comprobar como, tras esta inspección de cuentas que se acaba de reseñar, seguia desempeñando los dos oficios citados. Ver, por ejemplo, AGS, Libros de Cédulas de Cámara, Ib. 14, n. 29 (Santa Maria del Campo, 3 de octubre de 1507). 
damiento de impuestos ${ }^{13}$. La única excepción a esta evidente uespecialización" financiera que se observa, tanto en la carrera de oficial regio de Juan Álvarez de Toledo, como en el devenir de sus negocios privados, es la concesión a su favor de las escribanias de Ponferrada y su tierra ${ }^{14}$.

\section{LAS ESCRIBANIAS SEÑORIALES DE LA VILLA DE PONFERRADA}

El pleito informa sobre las circunstancias que regian la provisión y ejercicio del oficio de escribano en Ponferrada durante su inmediato pasado señorial. Habia dos posibilidades a la hora de proceder a la provisión de este oficio: por via de gracia y merced, to que implicaba un ejercicio vitalicio del mismo; por via de arrendamiento, lo que suponia -al menos, teóricamente-cambios continuos y frecuentes en la personalidad de aquél que lo detentaba ${ }^{15}$.

En la villa de Ponferrada se recurria, concretamente, a la segunda de estas dos vias. Tal como indican todos los testigos preguntados al respecto, el difunto Conde tenia por costumbre arrendar la escribania; todos los años, cuando sus contadores Mayores procedian al arrendamiento de las diversas rentas, entre ellas entraba también la escribania, que era adjudicada a aquél que más ofrecia por ella ${ }^{i 6}$, sin que se entrara en otro tipo de consideraciones. Algún testigo afirma que el arrendador de la escribania solía, a su vez, subarrendarla a terceros ${ }^{17}$.

Más dificil es precisar la cantidad en la que solia arrendarse habitualmente el oficio, pues los testigos son incapaces de ponerse de acuerdo en este punto. El precio oscilaria desde una cantidad máxima de 10.000 maravedies ${ }^{18}$ hasta una cantidad minima de $2.000^{19}$, si bien la mayor parte de los testigos coinciden en asegurar que dicho precio habia de si-

${ }^{13}$ Por ejemplo, en 1491 arrendaba los diezmos y otros derechos de Baza y su tierra, por una cantidad global de 812.157 de maravedies. AGS, Escribania Mayor de Rentas, Ig. 55 , fol. 533 .

${ }_{14}$ Ver nota 5

${ }^{15}$ Ambas vias de provisión se precisan en los prolegómenos del pleito, cuando se establece el interrogatorio al que han de responder los testigos, fol. $3 r$.

${ }^{16}$ Si bien uno de los testigos, Juan de San Gil, fol. 13v, indica que el Conde no siempre concedia la escribanía a quien más ofrecia por ella, sino que «a las vezes la dava el dicho conde por menos a quien queria".

"Concretamente, se trata de Rodrigo de Barrientos, fol. $6 r$.

18 Tal como asevera Luis de la Noceda, fol. $7 \mathrm{~V}$.

${ }^{19}$ Según afirma Juan de San Gil, fol. 13v. 
tuarse en torno a los 5.000 ó 6.000 maravedies ${ }^{20}$. En cuanto a los escribanos que sirvieron el oficio bajo los auspicios del difunto Conde, tan sólo se ofrece un nombre, el de Arias Diez ${ }^{21}$, si bien hay que tener en cuenta que en el interrogatorio no se efectúa ninguna cuestión sobre este aspecto.

Aunque tampoco se plantea ninguna pregunta acerca de la opinión de los vecinos de la villa y tierra de Ponferrada sobre la adecuación o inadecuación de este sistema para el servicio de las escribanias, lo cierto es que aquéllos desmuestran cumplidamente a lo largo del proceso su escasa estima hacia los escribanos arrendadores, que -en su opiniónson foco de corruptelas y abusos de indole diversa ${ }^{22}$, si bien en ningún momento se produce ninguna alusión concreta en torno a abusos o corruptelas cometidas por escribanos que ejercieron su oficio durante el pasado señorial de la villa.

\section{JUAN ÁLVAREZ DE TOLEDO, ESCRIBANO DE LA VILLA DE PONFERRADA}

Aunque no es posible determinar con exactitud en qué momento se produce la provisión del oficio en su favor, es evidente que ésta sólo pudo tener lugar tras el sofocamiento de la sublevación protagonizada por el joven Conde de Lemos, una vez que Ponferrada habia pasado a integrarse en el realengo. Si que se puede ofrecer, sin embargo, una fecha aproximativa, pues una real provisión de los Reyes Católicos cuyo traslado se inserta en el pieito analizado, fechada en Granada, a 21 de julio de 1499, recoge una petición presentada por Juan Álvarez de Toledo ante los soberanos, en la cuál aquél afirma que ha estado en posesión del oficio durante doce años ${ }^{23}$, lo que parece indicar que la provisión se efectuó, muy probablemente, en algún momento indefinido del año 1487.

${ }_{20}$ En opinión de Alonso Fernándes, oscilaba entre los 6.000 y los 8.000 maravedies anuales, fol. 7r; para Fernán Folle, se situaba en 4.000 maravedies, fol. 9r; según Arias Carvajo, eran 4.000 ó 5.000 maravedies, fol. 10r. Finalmente, Bernal Gómez lo sitúa en una cantidad imprecisa entre 3.000 y 6.000 maravedies, fol. $12 \mathrm{v}$

${ }^{21}$ Tal como se verá más adelante. Arias Diez también sirvió el oficio con Juan Álvarez de Toledo.

22 Volveremos sobre esta cuestión a la hora de analizar el comportamiento de los escribanos que actuaron en la villa tras la concesión del oficio a Juan Álvarez de Toledo.

${ }^{23} \mathrm{Fol} .1 \mathrm{v}$ 
En cuanto a las circunstancias que propiciaron dicha provisión, los Reyes Católicos indican que se realiza en favor de Juan Álvarez Zapata "aviendo consideraçión a los serviçios que nos hizo en el çerco de las vyllas de Vyllafranca e Ponferrada, e los otros lugares del Bierço, e çiertas heridas que en ellos resçebió, a enmienda e remuneraçión dellos" ${ }^{24}$. No se indica en ningún momento porqué razón participó Álvarez de Toledo en el asedio de las citadas localidades, si bien se puede aventurar - conociendo sus posteriores actividades como oficial regio en Granada - la posibilidad de que hubiera sido pagador de las tropas que participaron en dichos cercos ${ }^{25}$.

Aunque la carta de merced en virtud de la cuál tuvo lugar el nombramiento no ha llegado hasta nosotros, la real provisión que estamos extractando añade que Álvarez Zapata obtuvo - junto con el nombramiento- la facultad de poder ejercer el oficio bien por si, bien por sus lugartenientes ${ }^{26}$. Álvarez de Toledo aprovechó cumplidamente esta facultad, pues lo cierto es que jamás sirvió el oficio por sí mismo, sino que en todo momento se valió de lugartenientes, a los que arrendaba la escribania; desde luego, si no hubiera mediado dicha facultad, nuestro hombre en ningún caso podria haberse beneficiado de la concesión del mismo, pues su condición de oficial al servicio de la Corona le impedía hacerse cargo directamente de la escribania de Ponferrada ${ }^{27}$.

Tal como ya queda dicho, Álvarez de Toledo arrendaba la escribanía a sus lugartenientes; no es factible determinar con qué periodicidad se procedia a este arrendamiento, pues la documentación no lo indica, pero si es posible precisar la cantidad que habian de satisfacer los arrendadores, que se cifraba en torno a los 10.000 maravedies anuales ${ }^{28}$, lo que

24 Ibidem.

${ }^{25}$ En este sentido, tal vez sea conveniente recordar que Fernando Álvarez de Toledo colaboró de forma destacada en la resolución del conflicto planteado por la sublevación del Conde de Lemos. El alcance de su actividad en relación con estos hechos se hace patente en la documentación relativa a los mismos conservada en AGS, Estado, lg. l-2.

${ }^{26} \mathrm{Fol} .1 \mathrm{v}$.

${ }^{27}$ A modo de ejemplo, resulta conveniente recoidar cómo en el momento en que se produce el pleito Álvarez de Toledo estaba avecindado en la ciudad de Granada, hecho en el que - por otra parte - incide toda la documentación posterior a 1492 relativa a este personaje.

${ }_{28}$ Todos los testigos interrogados muestran considerables coincidencias en este punto; se inclinan en favor de la cantidad de 10.000 maravedies Luis de la Noceda (fol. 4v), Juan Gallego (fol. 8r) y Fernán Folle (fol. 9v); por su parte, Rodrigo de Barrientos (fol. 6r), Bernal Gómez (fol. 13r) y Juan de San Gil (fol. 13v) apuntan que el arrendamiento se cifraba en 9.000 ó 10.000 maravedies. Finalmente. Alonso Fernández insiste en que la cantidad se situaba en torno a los 10.000 ú 11.000 maravedies (fol. $7 \mathrm{v}$ ). 
- a su vez - podría indicar que el arrendamiento suponia una periodicidad anual.

Hay que reseñar que la cantidad estipulada era satisfecha conjuntamente por aquellos lugartenientes que servian el oficio al mismo tiempo ${ }^{29}$. Se hace evidente el interés de Álvarez Zapata por obtener beneficio económico del ejercicio de la escribanía, interés que le había llevado a elevar considerablemente la renta que se pagaba por su arrendamiento con respecto a tiempos pasados.

La documentación también nos ofrece los nombres de aquellos que habian actuado como escribanos a las órdenes de Juan Álvarez de Toledo: Gómez Arias, Diego de Béjar, los hermanos Diego y Juan Boto, Arias Diez, Gómez Diez, Juan Gallarde (cuñado de los Boto), Alvar Garcia de Ribadeo, Bernal Gómez ${ }^{30}$ y Juan de San Juan ${ }^{31}$.

Una última cuestión que también nos aclara la documentación es la relativa al número de lugartenientes de que se valia habitualmente Álvarez Zapata para ejercer el oficio. La Mayor parte de los testigos afirman que usualmente servian el oficio dos o tres escribanos ${ }^{32}$, manifestando que el número ideal de estos oficiales que debian actuar en la villa y su tierra debía ser de tres, pues, tal como afirma Luis de la Noceda, "sienpre el uno es ausente, o doliente, o lo recusan por sospechoso" ${ }^{33}$.

Finalmente, para terminar con este somero análisis de la forma en que se ejercía el oficio de escribanía de la villa y tierra de Ponferrada mientras el mismo era ostentado por Juan Álvarez Zapata, habria que determinar el sentido de la actuación de sus lugartenientes, si la misma habia supuesto el aplauso de los vecinos, o si, por el contrario, habia impulsado sus quejas y protestas.

29 Tal afirma Fernán Folle, que debia de estar al tanto de esta cuestión, pues durante algún tiempo habia actuado como procurador de la villa de Ponferrada y su tierra (fol. $9 \mathrm{v}$ ).

${ }^{30}$ La lista es ofrecida por uno de los testigos del proceso, Luis de la Noceda (fol. $4 \mathrm{v}$ ).

${ }^{31}$ Este nombre es ofrecido por Fernán Folle (fol. $9 \mathrm{v}$ ). Los restantes testigos ofrecen listados muy parciales, coincidentes, en su fragmentariedad, con las aseveraciones de Noceda y Folie.

${ }^{32}$ Según atirman Luis de la Noceda (fol. 5v) Rodrigo de Barrientos (fol. $6 \mathrm{v}$ ), Alonso Fernández (fol. Tv), Juan Álvarez (fol. 12r), Bernal Gómez (fol. 12v) y Juan de San Gil (fol. 14r). Las únicas opiniones discordantes son las de Fernán Folle, que afirma que siempre actuaban tres escribanos (fol. 9v), y Arias Carvajo, que eleva el número de lugartenientes empleados normalmente por Álvarez de Toledo a tres o cuatro (fol. 10v).

${ }^{33}$ Este testigo recuerda cómo èsta era opinión generalizada en la villa (fol. 5r). Efectivamente, parece haber considerable acuerdo en este punto concreto. Tan sólo divergen Juan Gallego (fol. 8v) y Fernán Folle (fol. 9v), que indican que, dada la población de la villa y su tierra, podría bastar con dos escribanos. 


\section{LOS LUGARTENIENTES DE JUAN ALVVAREZ DE TOLEDO: LAS QUEJAS} DE UNA VILLA AGRAVIADA

Tal como ya queda dicho, durante doce años Álvarez Zapata ejerció el oficio a través de sus lugartenientes. Si bien el oficial regio afirma que durante ese lapso en que habia estado en posesión del mismo lo habia ejercido "syn contradiçión alguna, llevando los derechos e otras cosas que por razón del dicho ofiçio pertenesçian" ${ }^{34}$, lo cierto es que la villa se habia considerado agraviada por la actuación de los escribanos que servian el oficio en su nombre, situación que les habia impulsado a manifestar sus quejas ante los soberanos.

Dichas quejas debieron de parecer tan fundadas a los ojos de los propios monarcas y de sus consejeros que, a pesar de la condición de oficial regio de Juan Álvarez Zapata, a pesar también de la innegable influencia de su pariente, Fernando Álvarez de Toledo, se inclinaron en favor de la villa, cometiendo a su corregidor para que destituyera a los lugartenientes de Álvarez Zapata, sustituyéndolos por nuevos escribanos, escogidos por la localidad, en número suficiente para cubrir sus necesidades ${ }^{35}$.

Pero el pagador y despensero de los Reyes Católicos no estaba dispuesto a permitir que se le despojara tan fácilmente de su oficio de escribania de Ponferrada, por lo que aprovechó su cercania a los monarcas para solicitar que se le escuchara, asegurando que las quejas de la localidad no respondian a la realidad de los hechos, rogando que se abriera pesquisa en torno a la veracidad de las mismas. Isabel y Fernando accedieron a realizar la citada pesquisa, cometiendo su elaboración al nuevo corregidor de Ponferrada, Juan de Montalvo ${ }^{36}$.

El interrogatorio que se configura como base esencial de la pesquisa gira en torno a cuatro temas que debian de ser considerados como absolutamente esenciales ${ }^{37}$ : la forma de provisión de los oficios de escribania, con sus consecuencias en lo que se refiere a la estabilidad de los

${ }^{34}$ fol. $1 \mathrm{~V}$.

${ }^{35}$ El corregidor, Diego Sánchez del Castillo, se apresuró a cumplir las órdenes de Isabel y Fernando, reuniendo a la villa en consistorio, primero para decidir el número de escribanos que precisaba el ejercicio de la escribania de la villa y su tierra, y despues para nombrar a los tres nuevos escribanos: Antonio de Segovia, Hernando de Montoro y Diego Boto, que gozaban de la total y absoluta confianza de sus convecinos (ver las testificaciones de Luis de la Noceda, fols. 4r-6r).

${ }^{36}$ La orden es transmitida a través de la ya citada real provisión fechada en Granada, a 21 de julio de 1499, fols. 1r-2v, que incluye el interrogatcrio al que habian de contestar los testigos presentados por la villa.

${ }^{3}$ Dicho cuestionario queda reflejado en los fols. $3 r-4 r$. 
escribanos en el ejercicio del oficio ${ }^{38}$; Ias cualidades morales que debian de adornar a estos profesionales, asi como su cualificación profesional ${ }^{39}$; su actitud con respecto a la guarda y custodia de los registros donde quedaba constancia de las escrituras realizadas ${ }^{40}$; la cuantía de los derechos $y$ aranceles que cobraban por su trabajo ${ }^{41}$.

El primero de estos cuatro temas es, indudablemente, la cuestión clave, en torno a la cuál giran las demás. Ya se han mencionado las dos posibles vias de provisión de los oficios de escribania, asi como sus consecuencias desde el punto de vista de la vigencia temporal de dichos oficios. Los vecinos de Ponferrada y su tierra estaban acostumbrados, indudablemente, a que sus oficios de escribanía se cubrieran por via de arrendamiento, lo que implicaba la posibilidad de cambios cada vez que se procedia a un nuevo arrendamiento del cargo.

Asi se habia obrado en tiempos del difunto Conde de Lemos. Pedro López Osorio, y asi se habia obrado, igualmente, en tiempos de Juan Álvarez de Toledo. Sólo se quebranta esta costumbre cuando los Reyes Católicos desposeen del oficio a Álvarez Zapata, e imponen una solución que pasa por la designación de tres nuevos escribanos, por via de gracia y merced, es decir, con carácter vitalicio.

Los testigos muestran, por su parte, una evidente preferencia por la segunda de estas dos vias de acceso a los oficios de escribania: las de-

${ }^{38}$ Ciertamente, y tal como asevera Bono, J., Op. cit., págs. 210 y ss, son las diversas vías de acceso a los oficios de escribanía, así como las distintas modalidades que podian presentar cada una de esas vias, las que terminaron por provocar "el desorden y la irregularidad interna en el notariado", haciendo, pues, necesaria la reforma impulsada por los Reyes Católicos, una reforma en la que, a pesar de todo - y tal como se evidencia- seguía habiendo aspectos sin resolver.

${ }^{39}$ Ambos requisitos van intimamente unidos, pues uno y otro son imprescindibles para que el escribano pueda cumplir adecuadamente con sus funciones: la cualificación profesional es absolutamente imprescindible, pues el ejercicio del oficio exige el dominio de toda una serie de conocimientos, tal como pone de relieve Bono, J., Op. cit., pág. 221 y ss.; paralelamente, el escribano debia estar también en posesión de toda una serie de prendas morales, que le capacitaban para desempeñar de forma adecuada el oficio, mediatizado por toda una serie de prestaciones de carácter ético y moral (ver Bono, J., Op. cit., pág. 312 y ss.).

${ }^{40}$ Se trata de una de las principales tareas que ha de Hevar a cabo el escribano, absolutamente fundamental, pues es complementario al deber de asistencia que debia prestar a los particulares a la hora de la elaboración de sus escrituras. Para más información sobre esta cuestión, ver Bono, J., Op. cit., pág. 320.

${ }^{41}$ También esta cuestión quedaba regulada por la legislación, que imponia a los escribanos la existencia de unos aranceles máximos, que habian de ser respetados, so pena de tener que satisfacer fuertes multas pecuniarias, que podia, además, en algunos casos, ir acompañadas por castigos de Mayor importancia, tal como afirma Bono, J., Op. cit., pág. 339 y ss. 
claraciones en este sentido son muchas, y además muy tajantes. Así, por ejemplo, varios de los testigos no dudan en afirmar que la diferencia entre una y otra vía "es commo del çielo a la tierra», insistiendo en equiparar arrendamiento con tirania ${ }^{42}$, subrayando las múltiples consecuencias negativas que impone esta forma de provisión en el ejercicio de los oficios de escribania, y entre las que se cuentan los otros temas en torno a los que se mueve la pesquisa ordenada por Isabel y Fernando.

Si hay que creer a los declarantes, el arrendamiento de las escribanias implica, habitualmente, el nulo control sobre los requisitos, tanto personales como profesionales, que adornan a los que asi acceden a tan delicado oficio; favorece la proclividad de los nuevos oficiales a cobrar derechos excesivos, con objeto de lograr un rápido resarcimiento del desembolso efectuado al arrendar el cargo; finalmente, también presupone una evidente desidia de los escribanos arrendatarios a la hora de custodiar los registros, conectada con la inestabilidad que supone el ostentar un oficio por via de arrendamiento ${ }^{43}$.

Pasemos ahora a examinar las otras cuestiones que plantea el escrito de interrogatorio. Tema también de gran trascendencia es el relativo a las cualidades personales y profesionales que debian de exigirse a los escribanos. En este sentido, hay que hacer una necesaria referencia a los exámenes de acceso a la condición de escribano, exámenes donde se atendia cumplidamente a ambos aspectos, cruciales para asegurar un leal y adecuado servicio del oficio ${ }^{44}$. La superación de dichos exámenes suponía la entrega del título de escribano, que - al menos teóricamentedebia de ostentar todo aquel que deseara acceder al ejercicio de tal oficio.

Sin embargo, lo cierto es que no siempre se cumplia este fundamental requisito. Asi, los testigos interrogados por el corregidor de Ponferrada no dudan a la hora de afirmar que, de todos los escribanos que habian servido el oficio en nombre de Juan Álvarez Zapata, tan sólo uno de ellos,

${ }^{47}$ En palabras de Luis de la Noceda, "por tener la dicha escrivania en renta husavan más tiranamente del dicho ofiçio, por sacar su ynterese" (fol. $5 r$ ).

${ }^{43}$ Ver, por ejemplo, el testimonio de Rodrigo de Barrientos, fols. 6r-7r.

44 Arribas Arranz, F., Op. cit., pág. 175, extracta los contenidos de uno de estos exámenes - AGS, Quitaciones de Corte, lg. 2--, realizado bajo los auspicios del autonominado Alfonso XII. El examinando tenía que probar su habilidad en las artes de la lectura y la escritura, demostrando, igualmente, su pericia de cara a la clasificación, archivo y custodia de escrituras. Finalmente, se hacia información sobre su reputación y cualidades morales. Si todo resultaba plenamente satisfactorio, se le elevaba a la condición de escribano, con la contrapartida de prestar juramento de lealtad y fidelidad al rey, quedando constancia en el libro registro de escribanos su suscripción autógrafa y su signo. Ver, igualmente, Bono, J., Op. cit., pág. 228 y ss. 
Diego Boto - quien, por cierto, es un de los integrantes de la terna impuesta tras la deposición de Álvarez de Toledo-- estaba en posesión del titulo de escribano ${ }^{45}$.

Lógicamente, esta circunstancia influía directamente sobre el ejercicio del oficio de escribania, que, de esta manera, quedaba abandonado en manos de personas que no habian demostrado fehacientemente su capacitación para ejercerlo; esto no quiere decir que no estuvieran cualificados para ello, pues varios testigos reconocen como algunos de los escribanos arrendadores reunian los requisitos pertinentes para ejercer el oficio, aún sin poseer el título ${ }^{46}$.

Pero bien es verdad que se trataba de la excepción que confirmaba la regla, que indicaba claramente la inoperancia de la mayor parte de los escribanos sin título, una inoperancia que podía, además, alcanzar grados realmente inaceptables, cuando sucedia que alguno de los arrendadores del oficio de escribania no era capaz de escribir, e incluso tampoco sabia leer, con las consecuencias que se pueden suponer ${ }^{47}$.

Otra cuestión es la relativa a las prendas morales que tenían que adornar a los escribanos: en este sentido, los lugartenientes no parecen haber concitado las quejas de los vecinos de Ponferrada y su tierra, que en ningún momento les achacan comportamientos o reputaciones incompatibles con el ejercicio de tan delicado oficio.

Otra cuestión que también suscitó una fuerte sensación de agravio entre los habitantes de la villa de Ponferrada y su tierra fue la referida al escaso interés de los escribanos arrendadores por la guardia y custodia de los registros, desinterés agravado por los frecuentes cambios que la via de provisión por arrendamiento llevaba aparejados. Los escribanos, cuando les llegaba ia hora de dejar el oficio, no parecian preocuparse

\footnotetext{
${ }^{45}$ Fernán Folle da cuenta de una curiosa anécdota relacionada con esta cuestión, pues recuerda cómo uno de los lugartenientes de Álvarez Zapata, Gómez Arias, se jactaba de estar, igualmente, en posesión del titulo de escribano; sin embargo, cuando la presentación del mismo la fue exigida por el testigo, que a la sazón era procurador de la villa, se excusó de presentarlo, amparándose en todo tipo de pretextos (fol. 9r).

${ }^{4}$ Por ejemplo, Fernán Folle no duda en afirmar que tanto Juan de San Juan como Arias Diez estaban cualificados para ejercer el oficio, pese a no tener título (fol. 9r).

${ }^{47}$ Esta información es suministrada por Alonso Fernández, que no indica la identidad de los asi aludidos (fol. 7r). Por su parte, Bernal Gómez, que actuaba como oficial a las órdenes de los escribanos, y que indudablemente debia estar bien informado sobre sus capacidades y habilidades, ratifica la queja generalizada contra la casi inexistente cualificación de muchos de los escribanos que habian actuado a las órdenes de Álvarez de Toledo (fol. 13r). Se destaca especialmente la escasa capacitación de Gallarde, a quien el corregidor Diego Sánchez del Castillo llegó, incluso, a prohibir ejercer el oficio (según Juan de San Gil, fol. 13v).
} 
excesivamente por el destino de sus registros, dejándolos en manos de cualquiera, e incluso confiándoselos a quienes les pagaban por obtenerlos $^{48}$.

En estas circunstancias, las escrituras archivadas en los registros se perdian y traspapelaban con suma facilidad, acarreando graves perjuicios a los vecinos de Ponferrada y su tierra que habian recurrido a los servicios de los escribanos. Los ejemplos aducidos en este sentido son muchos y muy significativos. Uno de los declarantes, Juan Álvarez, relata el episodio en el que se vio envuelto él mismo; rea!izó unas escrituras ante un escribano venido de Astorga, y que apenas estuvo un año sirviendo el oficio en Ponferrada, para regresar después a su tierra de origen. Cuando el testigo, envuelto en un pleito, trató de obtener dichas escrituras, descubrió que las mismas se habian extraviado, razón por la que perdió el pleito ${ }^{49}$.

Similar es la experiencia vivida por Rodrigo de Barrientos, al que le perdieron una escrituras de compra-venta por valor de 50.000 maravedies, ocasionándole grandes perjuicios ${ }^{50}$. Por su parte, Arias Carvajo afirma -aunque sin dar datos concretos-que fueron muchos los que, a pesar de pagar por la elaboración de sus escrituras, no consiguieron obtenerlas, con las funestas cosecuencias que esto implicaba para los así perjudicados ${ }^{51}$.

La última de las cuestiones en torno a las que gira el interrogatorio es la relativa al cobro de derechos excesivos por parte de estos escribanos arrendadores, algo que también debia de estar a la orden del día, a tenor de las información que en este sentido suministran los testigos. Uno de éstos no duda en calificarles de "onbres alcançados" ${ }^{52}$, aseveración que parecen ratificar los demás declarantes, que recuerdan continuamente que ninguno de los que habian arrendado el oficio a Álvarez Zapata se distinguia por su fortuna ${ }^{53}$.

Este hecho, la elevada renta que se pagaba por la escribanía, y el no excesivo provecho que podia obtenerse de la misma propiciaba la ten-

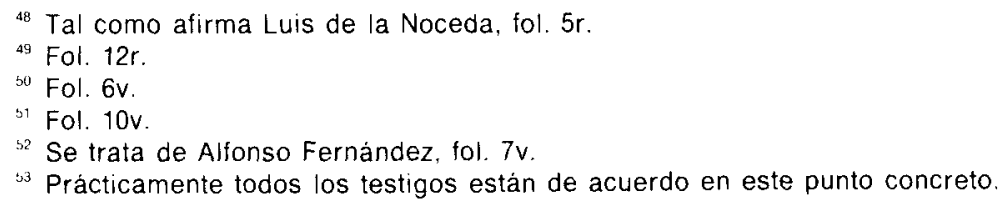


dencia a cobrar derechos excesivos ${ }^{54}$. También en este caso, los declarantes aducen numerosos testimonios para ratificar sus afirmaciones; Luis de la Noceda recuerda que Juan Boto cobró derechos excesivos a Pedro de Fresnedo por la realización de unas escrituras relativas a un proceso ${ }^{55}$. Juan Álvarez afirma que en una ocasión los escribanos se negaban a escribirle unas escrituras, ya que él, por su parte, se negaba a pagar la cantidad que le exigian por ese trabajo, pues era excesivamente elevada ${ }^{56}$.

El asunto llegó a tomar tal cariz, que el concejo de Ponferrada decidió establecer una tabla de derechos, estipulando que todos los escribanos debian acogerse a la misma, pero lo cierto es que jamás fue puesta en práctica, pues desapareció, y era clamor popular que los escribanos habian sido los autores de dicha desparición ${ }^{57}$.

\section{LA SOLUCIÓN DEL CONFLICTO: PONFERRADA NOMBRA A SUS PROPIOS ESCRIBANOS}

Tal como ya queda dicho, las quejas de los habitantes de Ponferrada y su tierra surtieron efecto, y los soberanos apartaron del oficio a Juan Álvarez de Toledo, permitiendo a la villa nombrar sus propios escribanos, un nombramiento que se efectuó por via de gracia y merced, vitalicio, lo

$5^{4}$ Asi describe la situación Bernal Gómez, que asegura que «heran personas non ricas, y que cree que hera mucha cabsa de llevar los derechos demasyados, por estar la dicha escrivania en tan gran preçio subida, segúnd la dicha escrivania es de poco provecho" (fol. 13r). De la misma opinión es Alfonso Fernández, que indica que cree que la causa de la exigencia de derechos excesivos radicaba en "la dicha escrivania estar tan subida en renta, y sy de alli no la sacavan, vendieran eso poco que tanian, e aún asy lo vendian para pagar el dicho arrendamiento" (fol. $7 \mathrm{v}$ ).

ss El escribano llevó por su trabajo nada menos que dos castellanos de oro; su cliente, sintiéndose agraviado, protestó ante la justicia, que estableció el precio de los servicios del escribano en 246 maravedies, ordenándole devolver a Fresnedo la cantidad cobrada en exceso (fols. $4 v-5 r$ ).

sti Fol. 12r

${ }^{57}$ La información la ofrece Juan Álvarez, aunque no aclara porqué razón el concejo no perseveró en esa línea de actuación, y promulgando nuevamente la tabla y tratando de lograr su cumplimiento; tal vez la razón hay que buscarla en la influencia que algunos de los escribanos podia ejercer sobre el concejo (fol. 11v). 
que supone no sólo la estabilidad de los escribanos, sino también su enraizamiento en la villa o ciudad a la que prestan sus servicios ${ }^{58}$.

Los escribanos que así acceden al oficio han tenido que demostrar previamente sus condiciones, tanto morales como profesionales; frente al revuelo que generó en Ponferrada la escasa cualificación de muchos de los escribanos nombrados por Juan Álvarez de Toledo, se sitúa el exquisito cuidado que puso la villa a la hora de nombrar a la terna que los sustituyó, buscando personas en posesión del título de escribano, asi como también de todos los requisitos, tanto personales como profesionales, que habian de ser exigidos a estos profesionales.

También a la hora de valorar su celo en la guarda y custodia de los registros los testigos consideran positivamente a los nuevos escribanos; frente al descuido constante de los lugartenientes de Juan Álvarez de Toledo, se coloca el esmero de los tres escribanos nombrados por la villa tras la destitución de Álvarez Zapata, pues la terna siempre estaba atenta a mantener el orden adecuado sobre los registros; al fin y al cabo, al ser su permanencia al frente del oficio vitalicia, ellos son los primeros interesados en mantener las copias de las escrituras debidamente ordenadas ${ }^{59}$, dándose asi por terminado el desgraciado episodio que habia supuesto la desidia en la conservación de los archivos notariales de la villa, y las funestas consecuencias que habia tenido para algunos de sus moradores.

Igualmente, también se destaca como los nuevos escribanos dejaron de llevar derechos excesivos por la elaboración de las escrituras - los testigos lo achacan al hecho de que no se veían acuciados por la necesidad de paliar desembolsos económicos realizados con anterioridad-, lo que implicó un considerable alivio para los vecinos de Ponferrada y su tierra, que pudieron olvidar la rapacidad de los anteriores escribanos.

\footnotetext{
${ }_{58}^{8}$ Uno de los testigos, Juan Álvarez, se queja de los muchos escribanos que, como consecuencia de la via de arrendamiento por la que se proveía el oficio, han pasado por Ponferrada, añadiendo, en tono de queja, que muchos de ellos no eran naturales de Ponferrada y su tierra (fol. 11r). Por su parte, Luis de la Noceda relaciona la desidia en la custodia de los registros con la presencia de escribanos forasteros, que no se cuidaban de lo que pudiera pasar con sus archivos tras su marcha (fol. 5r). Juan de San Gil ofrece algunos datos sobre la procedencia de dichos escribanos forasteros, aseverando que muchos de ellos procedian de Galicia o de Astorga (fol. 14r). Por otra parte, conviene recordar que el enraizamiento en la localidad en la que se ha de ejercer el oficio es requisito al que se alude frecuentemente en la legislación, tal como afirma Bono, J., Op. cit., vol. II, pág. 219-220. Bien es verdad que este autor reconoce también que se trata de un requisito desatendido con harta frecuencia.

${ }^{59}$ En estas cuestiones insiste, por ejemplo, Alonso Fernández, fols. $7 r+8 r$.
} 
Por si todo esto fuera poco, además, la provisión por vía de gracia y merced colma la ansiada aspiración de controlar directamente el nombramiento de los escribanos de número, aspiración común a muchas de las ciudades y villas del reino, que se amparaban para ello en las Ordenanzas en este sentido otorgadas por Juan II en las Cortes de Madrid de 1435, ordenanzas que permitían a todas las ciudades y villas del reino elegir a sus escribanos, presentando una terna de candidatos al monarca, que escogeria de entre los tres aspirantes a aquél que fuera más de su gusto ${ }^{60}$.

Bien es verdad que en muchos casos no se trata, simplemente, de un anhelo presidido por el afán de aupar al oficio a hombres cualificados y capaces de ofrecer a la localidad correspondiente el mejor servicio, pues en múltiples ocasiones esconde el deseo de favorecer bien a los mismos miembros de las oligarquias locales de poder, bien a personas relacionadas con aquéllas. Sea como sea, parece que, en este caso concreto, la provisión realizada por la villa colmó todas las expectativas de sus vecirios y moradores.

Efectivamente, todos los testigos interrogados pueden afirmar que Antonio de Segovia, Hernando de Montoro y Diego Boto cumplen todos los requisitos legales exigibles, manifestándose, además, contentos con la forma que tenian de ejercer el oficio, manifestando su satisfacción con la forma en que se habia solucionado el conflicto que les habia enfrentado a Juan Alvarez Zapata ${ }^{61 .}$

\section{CONCLUSIONES}

Evideritemente, las quejas de la villa y tierra de Ponferrada contra los lugartenientes de su escribano de número, Juan Álvarez de Toledo, ma-

60. Estas ordenanzas han sido extractadas y comentadas por ArRibas ArRanz, F., Op. cit., pág. 185. Bien es verdad que fueron revocadas apenas un año después, en nuevas cortes celebradas en 1436, en las que se limitaba la elección directa de escribanos por parte de las villas y ciudades a aquéllas que disfrutaran previamente de privilegio específico en ese sentido, imponiéndose el nombramiento regio directo en aquéllas que no contaran con el citado privilegio (Arribas Arranz, F., Op. cit., págs. 186-187).

${ }^{6}$ Sólo uno de los testigos diverge de esta opinión a la hora de enjuiciar a los nuevos escribanos: se trata de Arias Carvajo, que afirma que Antonio de Segovia, por su profesión de trapero, que le obligaba a ir de feria en feria, descuidaba el oficio de escribano, si bien se apresura a añadir que gozaba de buena reputación entre sus convecinos y estaba sobradamente cualificado para ejercer como escribano (fol. $11 r$ ). 
nifiestan cierta inoperancia por parte de la reforma de la institución notarial auspiciada por los Reyes Católicos. A pesar del efectivo interés que mostraban los soberanos a la hora de establecer las nuevas lineas directrices que habian de seguir los escribanos de sus reinos y señoríos, lo cierto es que aún existian importantes lagunas, que podian llevar aparejado el incumplimiento de algunos de los puntales esenciales sobre los que se asentaba la reforma, como puede ser el relativo a la capacitación profesional de los escribanos, el aspecto que, indudablemente, más preocupaba a los monarcas ${ }^{62}$.

Incluso, se hace patente como, al menos en algunas ocasiones, de las que el presente episodio es ejemplo paradigmático, eran los propios Reyes Católicos los que quebrantaban, si no la letra, si al menos el espíritu de su propia reforma, realizando nombramientos cuyas positivas consecuencias en lo que se refiere al servicio del oficio eran cuando menos dudosas.

En estos casos, sólo quedaba una vía abierta ante la localidad asi perjudicada: luchar por la obtención de unos oficiales capaces y adecuados, reclamando la necesidad de cubrir los aspectos profesionales fundamentales, denunciando los posibles incumplimientos e irregularidades. Esta forma de actuar tiene un gran interés desde nuestro punto de vista, pues nos permite conocer cuáles eran aquellos aspectos en relación con el ejercicio del oficio de escribanía que, desde el punto de vista de los contemporáneos, quedaban revestidos de una mayor importancia.

Asi, se hace obvio el interés por lograr el enraizamiento y la estabilidad de los escribanos en la localidad en la que ejercen su oficio, un interés que radica en la necesidad de incentivar a estos profesionales para que sirvieran el oficio de la manera más esmerada y cuidadosa posible. También se hace hincapié en la necesidad de contar con escribanos que reúnan todos los requisitos exigibles, tanto profesionales, como de indole ético y moral, pues unos y otros eran esenciales para el correcto desenvolvimiento de su actividad.

Igualmente, se insiste en dos puntos relativos al ejercicio concreto del oficio cuyo incumplimiento podia acarrear muy serios problemas a los vecinos de villas y ciudades: se trata de la correcta guarda y custodia de los registros, algo primordial, pues su descuido podía significar perjuicios como los que se han citado páginas atrás. Finalmente, también se observa la necesidad de evitar la rapacidad y codicia por parte de estos pro-

${ }_{62}$ Recuérdese la insistencia de la legislación en este sentido, Bono, J., Op. cit., vol, II. pág. 293 y ss. 
fesionales, simplemente recurriendo a hacer cumplir las tablas de derechos fijadas por ley.

Esta via, con harta frecuencia, llevaba a una segunda lucha, por acceder al nombramiento y control de sus propios escribanos, logro que no siempre tenía las consecuencias apetecidas, pues el nombramiento por parte de villas y ciudades tampoco era la panacea de todos los males que afectaban a la institución notarial.

Finalmente, se hace patente que la legislación en materia notarial, aparentemente tan estricta y rigurosa, no siempre se cumplía en la práctica, y de hecho se podian llegar a conculcar hasta los aspectos más fundamentales de la misma, y, lo que es más grave, esta conculcación podia verse apoyada, en mayor o menor medida, por los propios monarcas, que asumían la paradoja de impulsar una legislación muy restrictiva, al tiempo que procedian a realizar nombramientos que, por las propias circunstancias de los asi favorecidos, cuando menos portaban el germen de la desatención y la ineficacia. 